\title{
Sanciones por violencia patrimonial debido al impago de la obligación de alimentos
}

Penalties for patrimonial violence due to the non-payment of the maintenance obligation

Autor: Camilo Andrés Ibarra Sánchez

Para citar este artículo:

Ibarra Sánchez, C.A. (2020). Sanciones por violencia patrimonial debido al impago de la obligación de alimentos. Revista Derecho y Realidad, 18, (35),

$189-214$

Derecho y Realidad | ISSN Impreso 1692-3936 | ISSN En línea 2619-5607

Vol. 18 - Número 35 | Enero - Junio de 2020 | pp. 189 - 214

DOl: https://doi.org/10.19053/16923936.v18.n35.2020.11908



\section{SANCIONES POR VIOLENCIA PATRIMONIAL DEBIDO AL IMPAGO DE LA OBLIGACIÓN DE ALIMENTOS*}

Penalties for patrimonial violence due to the non-payment of the maintenance obligation

\section{Camilo Andrés Ibarra Sánchez ${ }^{1}$}

ibarra.camilo.abogado@gmail.com

Recepción: 22 de agosto 2020

Aceptación: 1 de septiembre 2020

\section{RESUMEN}

En la actualidad, son muchas las personas, tanto hombres como mujeres, con la obligación de pagar alimentos (o mantener) a sus exparejas. Sin embargo, de manera injustificada, se rehúsan a realizarlo. Lo cual genera, en la persona alimentada, una condición de vulneración a sus derechos adquiridos, además de soslayar derechos humanos por situaciones de discriminación independientemente del género de las personas, tanto alimentante como alimentada.

En ese orden de ideas, el presente estudio pretende establecer que el incumplimiento injustificado a la obligación de alimentos se materializa como el desarrollo de la violencia patrimonial que, a su vez, es una interpretación de la violencia intrafamiliar. Por tanto, en concordancia con la inasistencia alimentaria, se presenta violencia intrafamiliar, con sus respectivas sanciones.

Para ello, se abordó la problemática desde los tipos de violencias, las características de la obligación alimentaria y una comparación con ordenamientos jurídicos extranjeros con miras a determinar la aplicabilidad de medidas útiles para evitar, o sancionar, el incumplimiento de tal obligación. Lo anterior, para deprecar que la violencia patrimonial, por impago de

*Artículo de reflexión, presentado con fines investigativos particulares del autor, para la revista "Derecho y Realidad" de la Facultad de Derecho y Ciencias Sociales de la Universidad Pedagógica y Tecnológica de Colombia - Uptc, Tunja, en calidad de Docente catedrático externo del Área de Derecho Privado de la mencionada Facultad.

I. Magíster en Derechos Humanos de la Universidad Pedagógica y Tecnológica de Colombia - Uptc, Abogado de la Fundación Universitaria Juan de Castellanos. Maestrando en Derecho Privado, Persona y Sociedad con Énfasis en Responsabilidad Contractual, Extracontractual Civil y del Estado, de la Universidad Externado de Colombia (Bogotá). Docente catedrático externo de la Universidad Pedagógica y Tecnológica de Colombia - Uptc - Área de Derecho Privado, sede Tunja; Docente de la Universidad Santo Tomás de Aquino Educación Abierta y a Distancia (VUAD); Docente cátedra de la Escuela de Policía "General Rafael Reyes" (ESREY) de Santa Rosa de Viterbo (Boyacá); Miembro fundador, director general y abogado litigante de "In Ius Vocatio Attorneys - Legal Support" (Bufete jurídico); litigante en causas de Responsabilidad Civil (contractual y extracontractual), del Estado, culpa patronal y responsabilidad fiscal.

Contacto: camiloandres.ibarra@uptc.edu.co; ibarra.camilo.abogado@gmail.com 
obligaciones de alimentos, puede ejercerse independientemente del género del sujeto pasivo y existe multiplicidad de procedimientos para la sanción de tal situación.

\section{PALABRAS CLAVES}

Violencia de género; violencia patrimonial de género; impago de obligaciones de alimentos; sanciones por incumplimiento de obligaciones alimentarias.

\section{ABSTRACT}

Today, many people, both men and women, are required to pay (or support) their ex-partners. But, sometimes, in an unjustified way, they refuse to do that. This generates, in the fed person, a condition of violation of their acquired rights, in addition to evading human rights by situations of discrimination regardless of gender of the people.

The present study seeks to establish that unjustified failure to comply with the obligation to provide food is materialized as the development of patrimonial violence which, in turn, is an interpretation of domestic violence. Therefore, in accordance with the lack of maintenance, there is domestic violence, with its respective sanctions.

To this end, the problem was addressed from the standpoint of the types of violence, the characteristics of the maintenance obligation and a comparison with foreign legal systems with a view to determining the applicability of useful measures to prevent, or punish, failure to comply with that obligation. This was done in order to clarify that violence against property, due to non-payment of maintenance obligations, can be exercised independently of the gender of the subject and that there are multiple procedures for sanctioning such a situation.

\section{KEYWORDS}

Gender violence; patrimonial violence of gender; non-payment of maintenance obligations; penalties for breach of maintenance obligations.

\section{INTRODUCCIÓN}

Se ha creado el imaginario social de que las obligaciones alimentarias van encaminadas a proteger, en primera instancia, los derechos de menores cuando alguno de sus padres no convive ellos. Sin embargo, existen diferentes apreciaciones de tal obligación, como en la que se debe el cónyuge culpable ${ }^{1}$ al inocente, a los padres, e inclusive al cónyuge aun en convivencia cuando no posee los medios, y los modos, para su propia subsistencia (Congreso de la República de Colombia, 1887).

Así, de dicha obligación se ha desprendido, por medio de desarrollo legislativo y jurisprudencial, una serie de interpretaciones de diversa índole, vinculando características $y$ formas en las que se puede configurar tanto la protección del derecho a ser alimentado como la obligación de responder por tales emolumentos. Lo cual permite observar, como parámetro del presente estudio, la forma en la que alguno de los cónyuges debe alimentos al otro en los casos mencionados previamente, dígase, la obligación del cónyuge causante de la disolución marital como en el caso del cónyuge dependiente.

De la circunstancia anterior se depreca que los alimentos son tanto un derecho para una parte en una relación jurídica -, como un deber - para la otra -. Así pues, su incumplimiento debe acarrear una sanción para la parte incumplida, cumplida defectuosamente o cumplida tardíamente. Por ello el legislador ha establecido diversas sanciones desde diferentes áreas, las cuales concuerdan con la forma de materialización del incumplimiento. Es decir, de una parte, las sanciones administrativas en la misma vía; las sanciones propiamente civiles $y$, de otra, finalmente, las penales como último recurso en caso de renuencia al

1. No es más que él o la cónyuge responsable de la disolución marital cuando se trata de un hecho atribuible a su responsabilidad. 
cumplimiento o reincidencia; siempre y cuando verse de manera probada una total falta de justificación al cumplimiento de la obligación de alimentos.

En concordancia con lo expuesto anteriormente, resulta primordial presentar una problemática latente en los ordenamientos jurídicos, particularmente, en el caso colombiano. Así, una de las controversias más marcadas dentro del objeto de estudio es la temática de género. Es decir, saber si se trata de una conculca de derechos cuando un hombre ejerce diferentes tipos de violencia sobre la mujer, ya sea física, psicológica, sexual, doméstica o, como se analizará en el presente escrito, patrimonial (Alberdi y Matas, 2002).

Por lo tanto, es pertinente establecer cada uno de los ejes principales de la presente investigación, entendidas como el objetivo hacia el cuál se dirige. Con lo cual se propone, como eje central, la pregunta: ¿Existe violencia patrimonial por el impago de obligaciones alimentarias, independientemente del sexo de la víctima y sus modalidades, y cuáles son las sanciones aplicables para refrenar la situación en Colombia?

Con el fin de desarrollar tal propuesta, se hace necesario presentar tres sub-ejes para sustentar lo precitado. En primer lugar; establecer las clasificaciones de violencia de género independientemente del sexo de las personas, incluyendo a la violencia patrimonial como nueva categoría conceptual dentro de la violencia intrafamiliar. En segundo lugar, determinar las características de la obligación de alimentos, las circunstancias y las sanciones que de ella se deprecan. Finalmente, realizar un breve estudio comparado con disposiciones normativas de otros Estados que han establecido que la violencia patrimonial es violencia intrafamiliar por el impago de prestaciones alimentarias.

El presente estudio resulta importante para poder amparar, por lo menos desde el punto de vista académico con miras a desarrollar en el derecho vivo, el máximo de derechos y calidades que tienen las personas consideradas víctimas dentro de la problemática. Adicionalmente, es posible observar la forma en la cual el tema resulta persistente socialmente, lo que requiere de un abordaje teórico y consecuente práctica. Más aún, tratándose de derechos de tan alta exigibilidad y necesidad.

Resulta conveniente aclarar, como se pretende demostrar a lo largo del estudio, que la violencia a tratar se extiende a todas las concepciones de género bajo el espectro de diversidad con la cual es posible identificarse. Situación que se demuestra con el informe presentado por la Comisión Interamericana de Derechos Humanos (2015), mediante el cual se manifiesta que la violencia de género se encamina a causar daños en la integridad y la psiquis de la víctima. Sin embargo, aquella última no puede solo pensarse en términos heteronormativos, hombre y mujer, sino que atiende a menoscabar las calidades de toda persona independientemente del sexo.

Asimismo, se presenta la necesidad de entender que las categorías de daño o de violencia son diversas, como se mencionó previamente, y que por cada una de esas categorías se pueden desprender otras formas, o ser independientes. En realidad, el simple hecho de causar un daño, por cualquier modalidad de violencia bien sea física, psicológica, doméstica o patrimonial, se menoscaba la integridad de los sujetos.

Por otra parte, resulta imperioso establecer los diversos mecanismos mediante los cuales se protege el derecho a recibir alimentos y las personas titulares de los mismos. Ello con el fin de esclarecer el sujeto sobre el cual recae la responsabilidad de sustento y, en caso de incumplimiento, hacerse acreedor de la correspondiente sanción, bien sea de tipo administrativo, civil o penal. A partir de ello, es posible enunciar lo fundamental que resulta abordar la temática desde las concepciones que se tienen de la obligación de alimentos, desde los tratados y acuerdos internacionales en materia de protección de derechos humanos. Particularmente en lo atinente a la asistencia alimentaria, para posteriormente recalcar las 
disposiciones legales y jurisprudenciales en el plano local (Colombia) en la materia. Con el propósito de determinar cuáles son los procedimientos para fijar la obligación y las sanciones en caso de impago.

Finalmente, el estudio pretende realizar un marco comparativo con algunos Estados que han adoptado medidas más drásticas en materia de incumplimiento a las obligaciones de alimentos. Principalmente, cuando se entiende por parte de esas naciones que dicho incumplimiento se configura como un tipo de violencia en contra del titular del derecho de alimentos, es decir, se causa una violencia patrimonial. Por tanto, resulta necesario sancionar y erradicar la conducta con medidas más fuertes. Para ello, se realizará una comparación con Venezuela, Panamá y España, pioneros en la imposición de sanciones más drásticas al tema de estudio.

\section{VIOLENCIA, GENERO Y PATRIMONIO}

El presente apartado pretende definir, lo más cerca posible, la violencia de género. Pretende esclarecer sus condiciones más relevantes, teniendo como punto de partida la violencia patrimonial, como una categoría que debe ser priorizada por el Estado para establecer políticas que permitan refrenar el fenómeno y, por tanto, hacerla susceptible de sanción. Lo cual se abordará en los apartados posteriores.

Así, en primer lugar, se procede a enmarcar la definición de la violencia de género, en segundo lugar, sus categorías $y$, finalmente, definir la violencia patrimonial desde su generalidad para luego aterrizar al tema de estudio.

\subsection{Definición de violencia de Género}

Socialmente se ha concebido que la violencia de género radica en un tipo de violencia manifestada de forma física, psicológica o de otras índoles, ejercida en contra de cualquier persona ${ }^{2}$ o, grupo de personas teniendo. Ello en consideración de la identidad y orientación sexual como base del ejercicio violento (Kilmartin \& Allison, 2007, pág. 278). Sin embargo, en algunas expresiones radicales sólo cabría entenderla de acuerdo al sexo (entendido como genitalidad) femenino ${ }^{3}$. Todo lo anterior, impacta de manera contraria en la identidad de los sujetos y, por ende, en su bienestar físico, económico, social, psicológico, etc.

La Oficina del Alto Comisionado para los Refugiados de la Organización de las Naciones Unidas (2003) estableció que, 'para distinguir la violencia común de aquella que se dirige a individuos o grupos sobre la base de su género' corresponde de manera directa con la definición precedente, lo que a su vez, de manera clara, se configura como una violación directa a los derechos humanos.

Dicha perspectiva es compartida por Human Rights Watch (2008), la cual determina que todo tipo de violencia que tenga como base situaciones de género o sexo, en sí mismo, se refiere a discriminación por condiciones específicas, lo que vulnera flagrantemente las prohibiciones de declaraciones, pactos y acuerdos en materia internacional referentes a la protección de derechos humanos. Lo anterior, sin menoscabo, claro está, de lo que implica en su naturaleza todo acto de violencia en contra de otro ser perteneciente a la especie humana.

Así, la violencia encaminada a situaciones de género se manifiesta de diferentes maneras. Algunas formas representadas en actos causantes de daño, sufrimiento, coacción, amenazas, coerción y restricciones a los diferentes tipos de libertades (personales, de locomoción, de pensamiento, etc.) (Pérez \& Escobar, 2011). Cabe resaltar que dichos actos se ven y materializan en todas las esferas de la vida y concreción

2. Desde el punto de vista de algunos sectores "progénero", esta es entendida única y exclusivamente en contra de las mujeres

3. Es de aclarar que en lo referente a sexo y género se deben tener en cuenta y apropiar las significancias de sexo y género 
humana, es decir, en lo social, lo político, lo laboral, lo familiar, las relaciones con el Estado, el sistema educativo de las naciones, los medios de comunicación, la sexualidad, las relaciones interpersonales, las religiones, organizaciones, asociaciones sociales y sindicales, la cultura, los espacios públicos, los medios de transporte, etc.

Usualmente, se ha generado la conciencia respecto de la violencia de género como aquella materializada, exclusivamente, en contra del género femenino (independientemente de la edad). Sin embargo, es conveniente aclarar que la violencia de género, desde las nuevas concepciones y categorías de esta clase, se manifiestan también en contra de miembros de las comunidades queer (Felson, Violence and gender reexamined, 2002).

Con base a lo anterior, es conveniente mencionar el argumento plasmado por la Organización de las Naciones Unidas, específicamente desde la Entidad de las Naciones Unidas para la Igualdad de Género y el Empoderamiento de las Mujeres (ONU mujeres, 2010). En dicha apreciación se establece como la violencia de género debe entenderse desde una concepción mucho más amplia que la que, exclusivamente, se dirige contra la mujer. Por lo tanto, resulta pertinente enfatizar que el tipo de violencia en estudio se dirige contra cualquier tipo de sujeto, frente la cual no se observa una clase de respeto a sus condiciones 'humanas'. Lo cual empeora a partir de la minimización de las cualidades sociales de su ser, y le atañe responsabilidad femenina y masculina, frente a la cual debe prevenirse de igual forma, independientemente de su edad ${ }^{4}$.

4. Resalta textualmente el pronunciamiento de las Naciones Unidas "Frecuentemente los términos "violencia basada en género" y "violencia contra las mujeres" son usados de modo indistinto en la bibliografía y por los abogados, sin embargo, el término "violencia basada en género" se refiere a aquella dirigida contra una persona debido al género que él o ella tienen, así como de las expectativas sobre el rol que él o ella deba cumplir en una sociedad o cultura. La violencia basada en el género pone de relieve cómo la dimensión de género está presente en este tipo de actos, es decir, la relación entre el estado de subordinación femenina en la sociedad y su creciente vulnerabilidad respecto a la violencia. Sin embargo, resulta importante advertir que tanto hombres como niños también pueden ser víctimas
Así, puede definirse a la violencia de género como todo tipo de violencia ejercida con fines de vulnerar la integridad y bienestar de una persona a causa de su sexualidad, identidad, género, condición sexual o genitalidad ${ }^{5}$. Especialmente cuando ello es usado de manera absolutamente intencional por medios forzosos de índole físico y/o psicológico. Puesto que dichas agresiones y daños, teleológicamente, se utilizan para manipular, coaccionar, limitar y minimizar a los sujetos pasivos de la misma, es decir, quienes son objeto de esa violencia: las víctimas.

\subsection{Categorías de violencia de género}

Resulta primordial establecer las categorías de violencia de género que se tienen en la actualidad, con el fin de comprender el plano de acción en el que el presente documento se desenvuelve. Ello, con el único interés de poder llegar a detentar una nueva categoría de la que poco se ha hablado en estudios, pero que recientemente ha tomado gran auge.

\subsubsection{Violencia física}

Violencia en donde su característica principal es el acto contentivo de fuerza contra la corporeidad de una persona, cuyo riesgo, resultado y consecuencia puede verse manifestado en lesiones físicas o daños corporales, algunos de estos pueden ser: golpes, quemaduras, ataduras, estrangulamientos, apuñalamientos, lanzamiento de objetos, producir heridas con armas u objetos (punzantes o contundentes), etc. Se presume que este tipo de violencia es el que sería más fácil de demostrar, sin embargo, pueden existir imprecisiones para su demostración, bien sea por falta de atención médica o factores diferentes (Castillero, 2017). Como se ha vislumbrado en la realidad social, dicho tipo de violencia,

de la violencia basada en el género, especialmente de la violencia sexual"

5. Cabe aclarar que se trata de un abuso psíquico, relacional o psíquico. 
en muchos casos, deviene en la muerte de la víctima o persona objeto de la agresión.

Puede ser, entonces, aquella percibida por terceros, es decir, otras personas, y que, por razones obvias, se hace perceptible por las huellas que quedan en las víctimas de este tipo de violencia. Ellas son externas $y$, por ende, observan y objetivizan. Por tanto, se convierte en la más reconocida jurídica y socialmente.

\subsubsection{Violencia Psicológica}

La violencia psíquica o psicológica se manifiesta en la gran mayoría de los casos como una consecuencia de otro tipo de violencia, generalmente la física. Se materializa mediante insultos, desprecio, humillaciones, amenazas hacia la víctima, minimizando o quitándole valor social y/o emocional a la misma. Por ejemplo, en un ambiente laboral menospreciando las calidades y capacidades, o menospreciando de forma minimizante, la capacidad intelectual del sujeto pasivo de violencia. Por otra parte, se constituye la manipulación que genera en la víctima sentimientos de culpa frente a circunstancias que no le atañen, o, mediante la indiferencia, causando debilitamiento emocional. Lo cual, a todas luces, pone al victimario en posición de dominio sobre la persona y sus situaciones, sea hombre, mujer, niño, niña adolescente, LGBTIQ+. (García, 2005). Dentro de dicha categoría podrían incluirse otros tipos de violencia que llevan aparejado sufrimiento psicológico para la víctima y utilizan coacciones, amenazas y manipulaciones para lograr sus fines. En ocasiones puede devenir en violencia social, como una categoría de la violencia psicológica, en medida que el agresor o victimario pone a la víctima en restricción de contacto con el entorno, entiéndase por familia, amigos y amigas, conocidos, personas vecinas del lugar de habitación, etc., lo que genera una afectación respecto de la posibilidad de apoyo del entorno a la víctima.

De tal categoría suele desprenderse, por interpretación, la violencia económica y/o patrimonial, conforme a lo que se explicará en acápite posterior.

\subsubsection{Violencia doméstica contra el hombre ${ }^{6}$}

Es claro que, tratándose de la afirmación del presente título, se pueden generar diversas formas de pensamiento $\mathrm{y}$, como consecuencia, un debate amplio. Sin embargo, a pesar de que diferentes estudios ubican a la violencia de género como aquella perpetrada contra la mujer, existen estudios e investigaciones que afirman que las tasas de violencia de mujer hacia hombre - o casos en los que la víctima es el hombre independientemente del género de la pareja - son altas y, según algunos, equivalentes (Nowinski \& Bowen, 2012).

Se trata, pues, de una situación controversial, sobre todo, teniendo en cuenta la cantidad de casos que se presentan de violencia de género entendida exclusivamente contra la mujer. Existen sectores que se resisten a creer que dicha violencia pueda ser considerada con la calificación que se le da en la presente investigación, por lo que al hablar de igualdad se necesita equiparar todo tipo de violencia dirigida contra cualquier miembro de la humanidad y no realizar o llevar a cabo distinciones que, en sí mismas, causan una discriminación flagrante (House of Commons Home Affairs Office, 2008).

Ahora bien, al hablar de violencia contra los hombres, se hace relevante mencionar que puede provenir de las mismas causas y motivos de aquella violencia dirigida contra la mujer, es decir, las razones de estas violencias pueden ser las mismas (Felson, 2002).

El Grupo de Investigación de la Violencia Doméstica (2013), publicado en la revista Springer Publishing "Parthner Abuse",

6. Cabe aclarar que es la denominación que se le ha dado desde el sentido discriminatorio de género, habida cuenta que es conveniente abordar este tipo de violencia con fines a entender que en todas las violencias de género se debe extender a hombres y mujeres. 
menciona, y demuestra, que en los casos de violencia contra las mujeres y contra los hombres por situaciones domésticas o intrafamiliares las situaciones se equiparan en número y forma, es decir, tanto hombres como mujeres pueden, y son, víctimas y victimarios. Dicho de otra forma, sujetos activos y pasivos de las agresiones domésticas o intrafamiliares. Tal investigación llevó a que se mencionara que el "estudio sin precedentes" de la violencia doméstica conminara a la comunidad del mundo a reconocer a los hombres, también, como víctimas de violencia doméstica o intrafamiliar ${ }^{7}$ (Salem, 2013).

Sumado a la creencia general respecto de que, única y exclusivamente, los hombres son los victimarios de la violencia intrafamiliar o doméstica, está el hecho de que los hombres víctimas de violencia no denuncian las agresiones por vergüenza y temor sociales (Woods, 2015). De igual manera, la presente y otras formas de violencia contra el hombre cada vez son más minorizadas o poco reconocidas en el entender social, habida cuenta de lo que se generaliza en medios de comunicación (a través de los populismos mediáticos) y las denuncias que den fe de ello que, como se mencionó, son bajas (Das Dasgupta, 2002).

Cabe mencionar, que, en todo tipo de violencia contra el hombre, se configuran todas las categorías o clasificaciones presentadas previamente e inclusive la que se analizará a continuación, ya que, como se dijo, se pretende demostrar que todas las violencias son ejercidas en contra de la persona independientemente de sexo o la genitalidad del actor - sujeto activo de la agresión - y la víctima - o sujeto pasivo de la manifestación violenta -.

\subsubsection{Violencia Sexual}

Para algunos tratadistas de psicología la violencia sexual es una manifestación de la violencia física. Por cuanto la primera se

7. The Unprecedented Domestic Violence Study Affirms Need to Recognize Male Victims, como se denomina en inglés. refiere a todas aquellas situaciones en las que la víctima se ve forzada u obligada a materializar actos de índole y naturaleza sexual en contra de su voluntad y, por lo general, se ve inmersa la fuerza por parte del victimario. Sin embargo, se ve que la coacción se puede presentar de forma psicológica también, lo que pone a la violencia sexual en una categoría independiente por el elemento natural diferenciador de los otros dos tipos de violencia (Castillero, 2017).

Ahora bien, el psicólogo Oscar Castillero (2017) también afirma como No es necesaria la existencia o materialización de la penetración ni que en sí mismo se produzca acto sexual abusivo. Sin embargo, es común observar que este tipo de violencia se manifiesta, con mucha frecuencia, en las violaciones dentro de las parejas, cuando se obliga a la víctima a la prostitución o prestación de servicios sexuales o eróticos, cuando se obliga (en el caso de la mujer) a quedar en estado de gravidez o por el contrario a causarse un aborto, en las mutilaciones genitales tanto masculinas como femeninas, cuando se presenta acoso sexual (por ejemplo en el ambiente laboral o en los establecimientos educativos), los tocamientos indeseados (situación que se presenta en espacios como el transporte público), entre muchos otros actos de este tipo.

Inés Alberdi y Natalia Matas (2002) afirman que "Se ejerce mediante presiones físicas o psíquicas que pretenden imponer una relación sexual no deseada mediante coacción, intimidación o indefensión" (pág. 94). Cabe resaltar el punto tomado en el párrafo anterior, ya que, si bien es cierto, para las expertas mencionadas, podría entenderse que la violencia sexual es consecuencia de la física o la psicológica, el objeto al que va dirigida es la libertad sexual de la persona, no tanto su integridad física, sino la emocional o psicológica de la víctima.

\subsection{Violencia patrimonial como nueva categoría de violencia intrafamiliar}


Existen diversas formas en las que los expertos en la materia abordan la temática, como, por una parte, observar que dicha violencia es diferente a la violencia económica $\mathrm{y}$, de otra, considerarla en la misma ubicación y categoría.

Puede entonces, entenderse tal violencia como el conjunto de actos encaminados a ejercer un control o imponer limitaciones a la libertad (Alberdi y Matas, 2002) de la persona por la dependencia económica y/o patrimonial. Es decir, cuando la víctima ha llegado a ser tan minimizada que no se le permite acceder a un trabajo o por situaciones sociales, como la falta de estudios no puede acceder fácilmente a oportunidades laborales. Dicho sujeto depende económicamente de su agresor, lo que le impide desenvolverse por sus propios medios de manera económica.

En dicha categoría de violencia puede notarse el acto en el que el agresor o victimario controla el acceso a recursos económicos a la víctima, impidiéndole de toda manera posible que pueda trabajar a cambio de una remuneración, o, de otra parte, cuando la víctima labora de forma remunerada, que el victimario le exija y tome los ingresos que la víctima percibe, controlando gastos y tomándolo como si fuera propio (García, 2005).

La Xunta de Galicia, a través de la dependencia "Mujeres en Galicia" (2007), perteneciente a la Secretaría General de Igualdad, en España, aduce que tal violencia se presenta cuando el agresor priva de manera intencionada, sin justificación legal o social, a la víctima de todo recurso económico que permita un correcto desarrollo físico o psicológico incluyendo en ello a los hijos e hijas, o cuando se presenta discriminación en la distribución de los recursos de los miembros del hogar. Aunado a lo anterior, el victimario considera a la pareja incompetente e incapaz de una disposición clara y adecuada de los recursos, por lo que, podría gastar dichos recursos de manera inocua en bienes o servicios innecesarios.
En concordancia con lo anterior, cabe traer a colación una definición breve, pero adecuada, de la violencia patrimonial o económica de género dada por El Congreso de la República del Perú (2015, pág. 2), mediante Ley No. 30364 de 2015, en la que menciona en su artículo $8^{\circ}$, literal d.:

"La que se dirige a ocasionar un menoscabo en los recursos económicos o patrimoniales de la mujer, a través de la perturbación de la posesión, tenencia o propiedad de sus bienes, pérdida, sustracción, destrucción, retención o distracción indebida de objetos, instrumentos de trabajo, documentos personales, bienes, valores y derechos patrimoniales.

Ello no solo se trata de casos en los que el hombre es el victimario. Por lo cual, debe apreciarse la situación y el fenómeno de la violencia patrimonial como esa afectación de persona a persona, independientemente del género de victimario y víctima.

Ahora bien, la honorable Corte Constitucional de Colombia (2016) mediante la sentencia T-012, aduce que, en el tipo de violencia de carácter patrimonial, se utiliza el poderío económico para ejercer un control sobre las decisiones e inclusive el proyecto de vida de la pareja ${ }^{8}$. Según el alto Tribunal, dicho tipo de violencia es la forma mediante la que el agresor "controla todo lo que ingresa al patrimonio común" sin que medie importancia de quien haya obtenido o ganado dichas acreencias patrimoniales. Así, la titularidad de bienes, el manejo y control de las finanzas y todo emolumento, aunado al o los abusos que puedan provenir de las relaciones económicas, reposan en el victimario o la victimaria.

8. Es necesario mencionar que la Corte Constitucional hace referencia a la violencia patrimonial ejercida por parte del hombre a su pareja, habida cuenta que se trata de un caso particular, siendo el caso de dicha providencia en la que "Andrea" tutela sus derechos en contra del Tribunal superior de Bogotá por violar derechos fundamentales del caso contra su exesposo "Carlos Manuel"; y las sentencias "T" de ese alto tribunal versan sobre casos particulares como el presente. 
Aunque la corporación "SISMA mujer" (2016) menciona que la violencia patrimonial va dirigida única y exclusivamente en contra de la genitalidad femenina, es decir, que soslaya las condiciones de la mujer por situaciones económico-patrimoniales. Comparte el sustento respecto de la generalidad en la que aducen que la discriminación se presenta, por ejemplo, con la generación ${ }^{9}$ de la pobreza, definida como el empobrecimiento de la persona y el empeoramiento de las condiciones de vida aunado a la vulneración de Derechos Humanos. Además de la concentración de pobreza en la persona que recibe el agravio.

Se suma a lo anterior, por parte de la Corte Constitucional, en la sentencia de referencia, que existen algunos elementos que pueden o son tenidos en cuenta como actos discriminatorios o de violencia económica y/o patrimonial, algunos de ellos son:

- El ocultamiento de ganancias por cualquier medio cuando puede presentarse una demanda de separación o proceso que como consecuencia traiga el pago de indemnizaciones o el establecimiento de alimentos ${ }^{10}$.

- Las afectaciones que se hagan al patrimonio derivadas del incumplimiento de obligaciones provenientes de mutuos con o sin intereses, bancarias, deudas, etc.

- La titulación de bienes que se adquieren en común, solo a nombre de alguno de los cónyuges, haciendo compleja la reivindicación de los derechos comunes de la unión en el caso de una posible separación y/o divorcio.

Sin lugar a duda, la Corte Constitucional de Colombia abre la puerta al objeto de esta investigación, dado que establece, lo que

9. Haciendo referencia a las cuestiones de género, sin embargo, cabe aclarar que la Corte Constitucional menciona a la feminización de la pobreza.

10. Se subraya el primer apartado, habida cuenta que es la configuración propiamente del objeto de estudio de la presente investigación. para ese Tribunal representa, la condición de la violencia patrimonial de género en el posible caso de que una parte sea sancionada a la obligación de alimentos respecto del o la cónyuge inocente y, en caso de tenerles, sus hijos.

\section{LA OBLIGACIÓN DE ALIMENTOS, LAS SANCIONES QUE PROVIENEN DE SU IMPAGO Y SANCIONES POR VIOLENCIA INTRAFAMILIAR}

El presente apartado pretende determinar con claridad lo que representa la obligación de alimentos. Para ello, se estima conveniente empezar por las disposiciones en la materia desde la esfera internacional, es decir: pactos, tratados, acuerdos, etc., que traten el tema y hayan sido suscritos por Colombia. En segundo término, analiza las disposiciones normativas internas del ordenamiento jurídico colombiano. Para finalmente comprender las sanciones que acaecen al incumplimiento de la obligación alimentaria, particularmente en el Estado colombiano.

En primer lugar, resulta pertinente definir la obligación de alimentos para poder entenderlos desde los acuerdos, tratados, convenios y convenciones internacionales.

Aduce el tratadista mexicano Rafael Rojina Villegas $(2006)^{11}$ que la obligación de alimentos es la facultad que tiene una persona llamada alimentado o acreedor alimentario de exigir de otra persona denominada alimentante o deudor alimentario, emolumentos y elementos necesarios para subsistir. Teniendo en cuenta para su exigencia que exista una relación de parentesco ${ }^{12}$, adopción, matrimonio o divorcio $^{13} \mathrm{y}$, en algunas legislaciones - como la colombiana - padres, padres adoptantes, hijos adoptados, entre otros.

11. La cual puede ser una definición acertada para la regla general de definición de la obligación alimentaria. 12. Consanguíneo, de afinidad o civil.

13. Cuando el alimentado es el cónyuge no culpable del divorcio. 
Así las cosas, se procederá con la propuesta del acápite.

\subsection{Disposiciones internacionales en materia de derechos humanos y obligación alimentaria}

En el marco internacional y en especial el de protección de derechos humanos, existen diversas disposiciones, tanto generales como específicas, que regulan múltiples derechos y sus categorías, además de las subcategorías. Lo anterior nace en el afán de los Estados de propender por el respeto y la garantía ${ }^{14} \mathrm{de}$ los bienes jurídicos tutelables que le atañen al ser humano en su propia condición, la humana.

Atendiendo a esto, en 1948, un grupo de Estados promulgan la "Declaración Universal de Derechos Humanos" (DUDH) y, con ella, se da la positivación de un catálogo de derechos, de los cuales cualquier persona puede y debe hacer uso ${ }^{15}$. En dicha declaración se establece, prima facie, el derecho de alimentos o manutención, en donde el Estado debe procurar su cumplimiento y materialización, es decir, su garantía. Recita textualmente la DUDH (Asamblea General de las Naciones Unidas, 1948):

\section{Artículo 25.}

1. Toda persona tiene derecho a un nivel de vida adecuado que le asegure, así como a su familia, la salud y el bienestar, y en especial la alimentación, el vestido, la vivienda, la asistencia médica y los servicios sociales necesarios; tiene asimismo derecho a los seguros en caso de desempleo, enfermedad, invalidez, viudez, vejez u otros casos de pérdida de sus medios de subsistencia por circunstancias independientes de su voluntad.

2. La maternidad y la infancia tienen derecho a cuidados y asistencia

14. Obligaciones internacionales de los Estados en materia de protección de derechos, particularmente, humanos.

15. Adecuado y entendiendo los límites de cada uno. especiales. Todos los niños, nacidos de matrimonio o fuera de matrimonio, tienen derecho a igual protección social.

Aunque para muchos no sea una manifestación directa de una obligación alimentaria por parte de un alimentante (o deudor) a un alimentado (o acreedor), es el principio y esencia jurídica de dicha obligación, habida cuenta de la obligación del Estado por promover el desarrollo de ese bienestar.

Al analizar el artículo se pueden encontrar diversos elementos de la obligación alimentaria, a saber:

- Cuando se habla de "nivel de vida adecuado que le asegure, así como a su familia, la salud y el bienestar", la declaración presenta, de primera mano, el sustento jurídico de la obligación alimentaria. Para lo cual se tiene en cuenta como los alimentos van encaminados a suplir las necesidades del alimentado en sus condiciones, nivel y estilo de vida ${ }^{16}$.

- Se desprenden de esa definición declarativa "la alimentación, el vestido, la vivienda, la asistencia médica y los servicios sociales necesarios", elementos que por su naturaleza se encuentran amparados en la obligación de alimentos, principalmente necesarios.

- Como consecuencia los congruos que podemos observar en la manifestación de "los seguros en caso de desempleo, enfermedad, invalidez, viudez, vejez u otros casos de pérdida de sus medios de subsistencia por circunstancias independientes de su voluntad.", situaciones que son facultativas, tanto de alimentante como de alimentado.

Ahora bien, la Organización de las Naciones Unidas emite la Convención sobre la Obtención de Alimentos en el Extranjero (1956), que tiene como fin permitir de

16. Separándolos entre alimentos necesarios (los que son indispensables para el cumplimiento de ese nivel y vida dignos) y los congruos (encaminados a suplir otros espacios de la vida humana que, no siendo necesarios, ayudan a mejorar la vida del alimentado). 
manera eficiente a las personas la obtención de alimentos. Especialmente, cuando se pretende tener el derecho a ser suministrados por parte de otra persona en el momento en que el alimentante no se encuentre en el país o territorio del alimentado. Lo anterior, se pretende llevar a cabo mediante organismos jurisdiccionales y administrativos de las potencias que se hayan adherido al tratado, es decir, que lo hayan ratificado. Por su parte, La Corte Constitucional de Colombia, mediante Sentencia C-305 de 1999, declaró la exequibilidad de la Convención ${ }^{17}$.

Aduce la Corte Constitucional (Sentencia C - 305 de 1999) que el fin que persigue la Convención es dar solución urgente a las necesidades de una persona sin recursos de otra que, por el vínculo familiar, debe a la primera. Lo cual, en el afán de los Estados por proteger derechos que le corresponden a la humanidad en ciertas condiciones y la importancia de la adhesión a los tratados, más en la materia, hace imperioso que dichas obligaciones sean cumplidas $\mathrm{y}$, por demás, protegidos los derechos de las personas alimentadas.

Habida cuenta de lo anterior, queda claro que para las potencias que hacen parte de las Naciones Unidas y el interés del Estado colombiano, se encaminan a lograr una protección de un derecho humano. Por su parte, el Pacto Internacional de Derechos Económicos, Sociales y Culturales (en adelante "el PIDESC" o "el Pacto") (1966), en su artículo $11^{\circ}$ menciona las obligaciones de los Estados que suscriben el Pacto en términos del reconocimiento, en cuanto al nivel de vida adecuado de las personas incluyendo la alimentación y vestido ${ }^{18}$. Completa el Pacto con la siguiente obligación, de suma importancia, donde recae la obligación de las medidas de los Estados:

Los Estados Parte tomarán medidas apropiadas para asegurar la efectividad de este derecho, reconociendo a este

17. Hecha ley de la república de Colombia mediante la Ley 471 de 1998.

18. Que resultan ser algunos de los elementos de los alimentos congruos y necesarios. efecto la importancia esencial de la cooperación internacional fundada en el libre consentimiento. (Organización de las Naciones Unidas, 1966).

Se depreca de lo anterior la importancia obligacional de los Estados frente a la protección (mediante mecanismos internos y de cooperación internacional) efectivización y materialización de la responsabilidad alimentaria de sus súbditos. Es decir, el reconocimiento de tal situación como derecho humano de necesidad inmediata.

Al abstraer los catálogos de derechos al plano local, se hace presente la Convención Americana Sobre Derechos Humanos (o "Pacto de San José"19) (Organización de Estados Americanos, 1969), que, en su artículo 7.7., establece lo que será materia de estudio en acápite posterior, con la relevancia directa respecto de la obligación alimentaria, por lo cual, solamente se hace su mención para ser analizada posteriormente. Lo anterior, teniendo en cuenta que el derecho que se establece en el artículo citado es respecto de la libertad personal o de locomoción, y en el numeral de atención, se mencionan las capacidades de los Estados respecto de restringir esa libertad por incumplimiento de la obligación alimentaria.

Finalmente, se procede a mencionar y analizar una de las Convenciones más importantes suscritas por Colombia y a la que tal vez, en materia de protección de derechos humanos, menos importancia se le ha dado, o poco ${ }^{20}$ análisis.

Se trata, pues, de la Convención Interamericana Sobre Obligaciones Alimentarias (Organización de Estados Americanos, 1989) ${ }^{21}$, la cual establece una serie de procedimientos administrativos y jurisdiccionales encaminados a que los Estados suscriptores y ratificadores de la misma, adquieran un compromiso $\mathrm{y}$

19. Llamado así por cuanto su celebración se da en la ciudad de San José de Costa Rica, capital de la República de Costa Rica.

20. Nulo.

21. Ámbito de aplicación. 
lo ejecuten, respecto de los derechos y deberes de alimentos que se consagran en la Convención.

Así, es de notar la tan importante apreciación que hace la Organización de Estados Americanos al determinar que debe existir una protección respecto del acreedor de alimentos $^{22}$ por parte de los Estados. Ello anudado a la competencia interna y la cooperación internacional cuando se trate de casos como los previstos en la Convención Sobre Alimentos en el Extranjero que ya se mencionó. Es decir, la asistencia interna, la obligación de protección como derecho humano y la cooperación de los Estados Parte, son el elemento fundamental para que los derechos del acreedor de alimentos no se soslayen o limiten y que todo deudor de alimentos cumpla a cabalidad con su obligación, sin restricción de las sanciones que puedan acaecer de acuerdo con los ordenamientos jurídicos de los Estados.

Se debe observar con determinado cuidado el inciso segundo del artículo $1^{\circ}$ de la Convención Interamericana Sobre Obligaciones Alimentarias que dicta:

La presente Convención se aplicará a las obligaciones alimentarias respecto de menores por su calidad de tales y a las que se deriven de las relaciones matrimoniales entre cónyuges o quienes hayan sido tales. (Organización de Estados Americanos, 1989, art $1^{\circ}$ )

Se debe observar que la Convención no hace relación exclusiva respecto de los menores hijos, sino también de las relaciones conyugales que obliguen a alguno de los esponsales a dar alimentos y, lo extiende, a quienes han dejado de serlo. Ello pone en el panorama de obligación a condiciones como las observadas en los casos previos de violencia patrimonial, generando una relación directa en cuanto al incumplimiento.

Para completar este apartado final, se hace conveniente traer a colación la ley y l sentencia con las que se ha dado

22. U obligaciones alimentarias. reconocimiento jurídico a esta Convención ${ }^{23}$, tales son la Ley 449 de 1998 y la Sentencia C-184 de 1999. Sin embargo, vale acotar que, por la precisión respecto del Estado colombiano y las disposiciones nacionales frente a la obligación de alimentos, serán tratadas en el acápite inmediatamente siguiente.

\subsection{Disposiciones nacionales en Colombia, en materia de la obligación alimentaria}

Es bien sabido que en el ordenamiento jurídico colombiano existe la protección de derechos del alimentado y el deber que le asiste al alimentante en cuanto a su disposición y cumplimiento obligacional. Aunado a ello, como se mencionó previamente, existe un catálogo normativo ajustado y tendiente a regular y proteger los derechos de alimentación y la obligación en sí misma.

Por lo cual, aparece en el ordenamiento colombiano disposiciones de carácter civil $y$, como se dijo, un compendio de normas de carácter internacional, convertidas en leyes nacionales, encaminadas a cumplir con lo dispuesto en materia de alimentos. Por tanto, se procederá a analizar las disposiciones en una especie de orden cronológico en cuanto a su emisión, para abstraer los elementos nacionales de las obligaciones alimentarias.

Así, en primer lugar, se tiene el Código Civil colombiano (Congreso de la República de Colombia, 1887), en el cual se plasma

23. Aclarando que, en el momento en que el Estado colombiano ratificó dicho tratado se declara "a. La República de Colombia, en relación con el Artículo 1 de la Convención declara que de conformidad con el artículo 344 de la Constitución Política, los derechos de los niños prevalecen sobre los derechos de los demás: b. La República de Colombia, teniendo en cuenta la declaración anterior, en relación con el Artículo 3 de la Convención, manifiesta que de conformidad con su ordenamiento jurídico y sujeto a las reglas previstas en él, además de los acreedores a que se refiere el párrafo 2 del artículo 1 de la citada Convención, ésta se aplicará a favor de: o Los descendientes; o Los ascendientes; o Los hijos adoptivos; o Los padres adoptantes; o Los hermanos; o La persona que hizo una donación cuantiosa si no hubiere sido rescindida o revocada; o El compañero o compañera permanente que forman una unión marital de hecho." 
la obligación de alimentos y su regulación en el Título XXI del LIBRO PRIMERO (de las personas) en el artículo 411 y subsiguientes del mismo. Allí se establece, claramente, la existencia de titulares del derecho de alimentos, estos son: Cónyuge, descendientes, ascendientes, al cónyuge divorciado sin culpa ${ }^{24}$, a los hijos naturales, a los ascendientes naturales, hijos adoptivos, a padres adoptantes, a los hermanos y al que hizo una donación cuantiosa si no hubiere sido rescindida o revocada. De igual forma, el código establece - entre otras - las reglas, las clases $^{25}$, la capacidad, la prelación, la prueba, la necesidad, la tasación, la duración, la forma y cuantía de los alimentos.

En caso de configurarse cualquiera de las condiciones mencionadas previamente, la persona puede exigir a la parte alimentante la provisión de los alimentos. Sin embargo, resulta importante realizar claridad y precisión en que las condiciones de alimentado y alimentante permitan que se dé tal situación. Es decir, que el alimentado ostente el derecho y el alimentante la capacidad para proveerlos (Alineados, 2018).

De esa manera se puede observar que la legislación colombiana determina que, en cuanto a cónyuges en convivencia o divorciados, les asiste la obligación de alimentar en caso de que alguno de ellos no se encuentre en capacidad para obtener los suyos propios.

Lo anterior, abstraído a la ejemplaridad se puede observar de la siguiente manera:

i) En caso de que uno de los cónyuges en convivencia no tenga los medios sociales y/o económicos para su propio sustento,

24. Es decir, cuando uno de los cónyuges comete alguna culpa o causal de divorcio contenida en el artículo 154 del Código Civil, éste le deberá alimentos al cónyuge inocente.

25. Congruos y necesarios: Estas clases de alimentos se diferencian en que, por ejemplo, los congruos se caracterizan por permitir la subsistencia del alimentado de acuerdo con su posición, condición y nivel social (deportes, artículos de tecnología, etc.), y los necesarios cubrirán lo indispensable (necesario) para el sustento de una persona (Salud, educación, alimentación, etc.) el otro cónyuge le deberá alimentar y procurar su bienestar.

ii) En caso de cónyuges divorciados, cuando uno de ellos es el causante del divorcio por alguna de las causales contempladas en la legislación civil, tal le deberá a título indemnizatorio alimentos al otro cónyuge divorciado ${ }^{26}$.

En concordancia con lo anterior, ha establecido el Alto Tribunal constitucional de Colombia que:

La obligación alimentaria entre esposos se ve materializada en virtud del principio de reciprocidad y solidaridad que se deben entre sí, y por ende la obligación recíproca de otorgar lo necesario para garantizar la subsistencia cuando uno de sus miembros no se encuentre en posibilidad de suministrárselos por sus propios medios. Entre los esposos la obligación de solidaridad se despliega en los deberes de socorro y ayuda mutua que se originan por el vínculo matrimonial, los cuales pueden subsistir inclusive cuando media separación de cuerpos o su disolución. Valga señalar que esta Corporación ha indicado que en caso de disolución de la unión conyugal, las obligaciones de socorro y ayuda se reducen "en la medida en que las prestaciones de orden personal no siguen siendo exigibles"; pero, igualmente, se transforman, por cuanto "algunas obligaciones económicas pueden subsistir en condiciones específicas (Sentencia T-506 de 2011).

En concordancia cronológica legislativa de la regulación de alimentos en Colombia, como se mencionó en acápite anterior, se promulga, en Colombia, la Ley 449 de $1998^{27}$ (Congreso de la República de Colombia, 1998) por medio de la cual se le da vida

26. Puede darse también que, en el caso de cónyuges divorciados, uno de ellos le deba alimentos al otro por la custodia y cuidado de los menores hijos.

27. Por medio de la cual se aprueba la "Convención Interamericana sobre Obligaciones Alimentarias", hecha en Montevideo, el quince (15) de julio de mil novecientos ochenta y nueve (1989). 
jurídica al tratado denominado Convención Interamericana sobre Obligaciones Alimentarias. Dicho acuerdo internacional, hecho ley al interior del Estado colombiano, se convierte en una herramienta de orden internacional con efectos internos respecto de los procedimientos para el cumplimiento de las obligaciones de alimentos. Es así como en él se establecen procedimientos y compromisos de los Estados para la efectivización de ese derecho (para el caso del alimentado o acreedor) y deber (para el alimentante o deudor).

Como se advirtió previamente, entre los elementos importantes que se pueden observar de la Convención se observa el marco de aplicación contenido en el artículo primero, inciso segundo, que reza como las obligaciones alimentarias versan respecto de derechos de: i) Menores por la simple condición de serlo y no tener capacidad de auto sostenimiento. ii) Obligaciones alimentarias derivadas de relaciones matrimoniales. Es decir, entre cónyuges (uno respecto de otro y viceversa). iii) $\mathrm{Si}$ de dicha relación marital haya devenido un divorcio o separación, es decir, que en algún momento hayan sido cónyuges y ya no lo sean (Organización de Estados Americanos, 1989).

En tal orden de ideas, conviene hacer hincapié en la protección que debe el Estado a sus nacionales dentro del marco de materialización y concreción de Derecho Humanos, siendo los alimentos uno de ellos $^{28}$. Por tanto, dicho reconocimiento, así como la realización material y todas las características de los alimentos, poseen una relación y conexidad directas. Enfatizando la forma en la cual, la familia y sus miembros son el eje central del desarrollo social. Asimismo, al ser la institución más importante, recaen sobre ella los derechos y garantías fundamentales, establecidas constitucionalmente desde 1991 (Sentencia C - 184 de 1999).

28. Dentro de los derechos conocidos como Económicos, Sociales y Culturales.
Así, resulta imperioso efectivizar, materializar y proteger incesantemente dichas cualidades fundamentales en pro de garantizar los mínimos vitales de los sujetos. Los cuales hacen parte de la misma, o que, siéndolo en algún momento y por ciertas circunstancias ya no lo son, se hacen acreedoras del derecho a ser alimentados. Por ejemplo, los niños o quienes se encuentren en condiciones de debilidad manifiesta, al igual que aquellos inocentes de la desarticulación del núcleo familiar.

\subsection{Sanciones que acaecen al incumplimiento de obligaciones alimentarias en Colombia en conexidad con el proceso sancionatorio por violencia intrafamiliar}

El presente apartado pretende definir, establecer y conectar las sanciones y procedimientos para la obtención de alimentos, es decir, el proceso administrativo, el civil $^{29}$ en caso de incumplimiento; y el proceso penal en el mismo caso. Ello en relación con las sanciones que acaecen a otros delitos del marco familiar, como la violencia intrafamiliar.

Como se mencionó en el primer capítulo, la existencia de violencia patrimonial se puede entender como violencia intrafamiliar, claro está, dependiendo de las circunstancias que le atañen. Por lo tanto, se procederá a relacionar una condición con la otra para establecer un marco de sanciones en la concomitancia de conductas que afecten el derecho alimentario junto a la violencia intrafamiliar.

Resulta conveniente recordar la definición de la obligación de alimentos del tratadista Rafael Rojina Villegas (2006) tomado en acápites previos, en la que la establece como la facultad de una persona de exigir a otra ${ }^{30}$, dineros y elementos de

29. 0 de familia.

30. Entiéndanse y reitérense: Alimentado o acreedor; alimentante o deudor. 
absoluta necesidad para la subsistencia y que provengan de un vínculo de parentesco entre uno y otro. Entendiendo dicho vínculo como consanguíneo, de afinidad, civil o como consecuencia de una disolución marital.

La definición previamente mencionada hace referencia a la obligación de alimentos. No obstante, resulta necesario definir a los alimentos como tal. La Ley 1098 de 2006, indica que son aquello indispensable para la habitación, vestido, sustento, recreación, educación, asistencia médica, y todo lo que dentro de estas categorías y otras sean necesarias para el desarrollo integral del alimentado $^{31}$ (Congreso de la República de Colombia, 2006).

Se observa, entonces, la diferencia entre la obligación de alimentos y los alimentos mismos. La primera hace referencia a quién tiene el derecho a exigirlos y a quién se los puede exigir, mientras que la segunda hace referencia a las características. Es decir, lo que puede pedir y el derecho en cuanto a sus condiciones, exigibilidad y características. Por tal razón, menciona la Corte Constitucional de Colombia que:

El derecho de alimentos es aquel que le asiste a una persona para reclamar de quien está obligado legalmente a darlos, lo necesario para su subsistencia cuando no está en capacidad de procurársela por sus propios medios. La obligación alimentaria está entonces en cabeza de la persona que, por mandato legal, debe sacrificar parte de su propiedad con el fin de garantizar la supervivencia y desarrollo del acreedor de los alimentos (Sentencia C-156 de 2003, pág. 1).

Previamente se mencionó y describió a los alimentos necesarios y los congruos, sin embargo, resulta necesario hacer mención, dentro de la misma sentencia previamente citada que dichos emolumentos se deben al cónyuge divorciado no culpable de la separación. Vale aclarar que la interpretación

31. Entiéndase la expresión "alimentado" como hombre, mujer, niño, niña, adulto o adulta mayor, cónyuge inocente, etc. dada por vía jurisprudencial hace referencia directa a cómo se deben a la mujer o al hombre. Es decir, no se refiere directamente a su deber a las mujeres, lo cual extiende la interpretación y derecho hacia el hombre cuando (así como en el caso de la mujer) no es el culpable de la disolución marital (Sentencia C-156 de 2003).

Ahora bien, para comenzar con el proceso sancionatorio en materia de incumplimiento de obligaciones de alimentos, se remite al procedimiento para la obtención del pago de dicha obligación $\mathrm{y}$, en caso de incumplimiento, las sanciones civiles $\mathrm{y}$ penales que acarrea. Así, se conecta el primer capítulo, respecto del concurso de delitos, - si es el caso - con el de violencia intrafamiliar.

En caso de tratarse de menores que tienen el derecho a la obtención de alimentos, el tutor o padre a cargo, debe iniciar el trámite conciliatorio según las reglas de la Ley 640 de 2001 (Congreso de la República de Colombia, 2001). Dicha conciliación se puede solicitar y llevar a cabo ante la inspección de policía, Instituto Colombiano de Bienestar Familiar (ICBF), centro conciliatorio debidamente instituido o comisaría de familia. Lo anterior, con miras a intentar agotar una etapa en la que, voluntariamente y de manera equitativa, se llegue a un acuerdo entre el deudor de alimentos o alimentante y el tutor o padre de los menores. Ello con el fin de suplir las necesidades de los vulnerados. Con lo anterior, se surte el proceso "administrativo" de obtención de alimentos. En caso de existir acuerdo, la conciliación prestará mérito ejecutivo, lo cual significa que el incumplimiento, por parte del alimentante, dará lugar a la posibilidad de iniciar el proceso ejecutivo de alimentos ante la jurisdicción civil/familia ${ }^{32}$.

Cuando se incumple, o no se presenta, el acuerdo conciliatorio, se adelanta la etapa jurisdiccional. Es decir, impetrar demanda

32. En caso de no llegar a ningún acuerdo entre las partes, tanto solicitante como solicitada en la conciliación, también se legitima para continuar con las acciones jurisdiccionales, pero podrá imponerse una cuota alimentaria provisional. 
ante la jurisdicción pertinente al caso bajo la figura de proceso verbal sumario de alimentos. En dicho proceso, como lo establece la Ley 1564 de 2012 (Congreso de la República de Colombia, 2012), la parte demandante debe aportar los documentos con los cuales pretenda hacer valer la capacidad económica del demandado (alimentante) y prueba del vínculo jurídico del que provendrá la obligación alimentaria. Aunado a lo anterior, el juez fijará una cuota de alimentos "provisional", con miras a proteger los derechos del alimentado mientras se surte el proceso. Finalmente, en caso que el obligado a prestar los alimentos no cumpla con ninguna de las obligaciones que se le imponen por las vías previamente citadas, se tendrá la legitimación para interponer, dentro del mismo proceso, en cuaderno aparte, el proceso ejecutivo de alimentos. Ello con el fin de, por ejemplo, "ordenar al respectivo pagador o empleador de esa persona que descuente y consigne a órdenes del juzgado hasta el cincuenta por ciento $(50 \%)$ de lo que legalmente compone el salario mensual del demandado, y hasta el mismo porcentaje de sus prestaciones sociales" (Instituto Colombiano de Bienestar Familiar, 2019) o, de otra parte, ordenar el embargo de bienes en posesión del alimentante incumplido.

No obstante, en caso de que dicha obligación provenga de una relación entre cónyuges o de un proceso judicial donde se ordene el pago alimentario por parte del culpable ${ }^{33}$, el incumplimiento del

33. Se considera cónyuge o parte culpable en un divorcio a quien incurra en alguna de las causales siguientes (Código Civil, 1887), según el artículo 154: 1. Las relaciones sexuales extramatrimoniales de uno de los cónyuges; 2 . El grave e injustificado incumplimiento por parte de alguno de los cónyuges de los deberes que la ley les impone como tales y como padres.

3. Los ultrajes, el trato cruel y los maltratamientos de obra; 4. La embriaguez habitual de uno de los cónyuges; 5 . El uso habitual de sustancias alucinógenas o estupefacientes, salvo prescripción médica; 6. Toda enfermedad o anormalidad grave e incurable, física o síquica, de uno de los cónyuges, que ponga en peligro la salud mental o física del otro cónyuge e imposibilite la comunidad matrimonial (cuando la obtención de la enfermedad sea culpa de esa parte, por ejemplo, SIDA o ETS's). NOTA: Numeral $6^{\circ}$ declarado EXEQUIBLE por la Corte Constitucional mediante Sentencia C-246 de 2002, en el entendido que el cónyuge divorciado que tenga enfermedad o anormalidad grave e incurable, procedimiento ejecutivo de alimentos se continuará bajo las mismas reglas citadas.

Ahora bien, en caso de no cumplirse la obligación de alimentos emanada de los procedimientos anteriores, la parte afectada por el no pago de dicha obligación podrá acudir al reconocimiento y solicitud de sanción de la parte incumplida. Realizado, por vía penal por el delito de inasistencia alimentaria contenido en el artículo 233 (Congreso de la República de Colombia, 2000). Lo cual se representa por medio de la debida denuncia ante la Fiscalía General de la Nación, para que, conforme a las reglas constitucionales y legales, proceda con la acción penal que recae en sus atribuciones.

Es conveniente, pues, traer a colación el apartado legal que constituye la falta penal de inasistencia alimentaria del artículo precitado:

El que se sustraiga sin justa causa a la prestación de alimentos legalmente $\operatorname{debidos}^{34}$ a sus ascendientes, descendientes, adoptante, adoptivo, cónyuge o compañero o compañera permanente, incurrirá en prisión de dieciséis (16) a cincuenta y cuatro (54) meses y multa de trece punto treinta $y$ tres (13.33) a treinta (30) salarios mínimos legales mensuales vigentes.

La pena será de prisión de treinta y dos (32) a setenta y dos (72) meses y multa de veinte (20) a treinta y siete punto cinco (37.5) salarios mínimos legales mensuales vigentes cuando la inasistencia alimentaria se cometa contra un menor.

PARÁGRAFO 1o. Para efectos del presente artículo, se tendrá por compañero y

\footnotetext{
física o psíquica, que carezca de medios para subsistir autónoma y dignamente, tiene el derecho a que el otro cónyuge le suministre los alimentos respectivos.; 7. Toda conducta de uno de los cónyuges tendientes a corromper o pervertir al otro, a un descendiente, o a personas que estén a su cuidado y convivan bajo el mismo techo.
}

34. Apartado subrayado fuera de texto original, por lo que se hace hincapié teniendo en cuenta que es el centro del estudio. 
compañera permanente únicamente al hombre y la mujer que forman parte de la Unión Marital de Hecho durante un lapso no inferior a dos años en los términos de la Ley 54 de 1990. [...] (Ley 599 de 2000)

Así, se puede observar cómo, a partir de incumplimiento de las obligaciones alimentarias, devienen sanciones con carácter de restricción de la libertad personal. Sobre todo, teniendo en cuenta la importancia y el derecho del alimentado, al igual que su prevalencia en la protección de la familia y sus necesidades. Por ello resulta necesario aclarar que, para que el incumplimiento de las obligaciones alimentarias pueda ser impenetrado ante la jurisdicción civil o penal, debe tener un carácter injustificado o doloso por parte del alimentante.

Finalmente, como se mencionó al inicio del presente apartado, resulta necesario enlazar el delito de "inasistencia alimentaria" con el de "violencia intrafamiliar". Para lo cual, la legislación penal colombiana establece el artículo 229 (Ley 599 de 2000) modificado por la Ley 1959 de 2019 (Congreso de la República de Colombia, 2019). En él se proponen ciertas circunstancias a observar con detenimiento, puesto que, representan una serie de penas, entre cuatro a ocho años, privativas de la libertad a quien lo cometa en caso de infligir física o psicológicamente sobre algún miembro del núcleo familiar un daño o perjuicio. Ello aunado a la agravación de la pena cuando se trate de menores, mayores de sesenta años, mujeres o personas que se encuentren en "estado de indefensión o en cualquier condición de inferioridad" ${ }^{35}$ (Ley 1959 de 2019. Artículo $1^{\circ}$ ).

Adicionalmente, la norma contempla - frente a la violencia intrafamiliar características planteadas previamente, por ejemplo, el hecho de cometer la conducta contra cónyuges, compañeros permanentes -aunque exista divorcio o separación previa-, el padre o la madre, aunque no vivan juntos, por parte del otro.

35. Como se mencionó en el capítulo inicial respecto de la violencia patrimonial.
Por lo tanto, configurando todo lo anteriormente expuesto. tanto el delito de inasistencia alimentaria, a partir del orden psicológico, como la violencia intrafamiliar, configurada como consecuencia del punto anterior, se constituyen como violencia patrimonial.

\section{ORDENAMIENTOS JURÍDICOS QUE HAN ADOPTADO LA VIOLENCIA INTRAFAMILIAR, POR EL IMPAGO DE OBLIGACIONES ALIMENTARIAS, COMO HECHO SANCIONABLE}

En el presente apartado conviene resaltar los ordenamientos que han contemplado a la violencia patrimonial como interpretación del delito de violencia intrafamiliar. Ello se ha realizado encaminado a la protección exclusiva de la mujer, es decir, se considera violencia de género en contra de la misma. Por lo tanto, el actual escrito pretende tomar los elementos constitutivos de violencia patrimonial de esas disposiciones legales y amparar el marco general de comisión de la conducta. Es decir, aplicar el concepto de violencia patrimonial como violencia intrafamiliar, dirigido a cualquier persona independientemente del sexo, tanto del agresor económico como de la víctima.

\subsection{Venezuela}

El más cercano ejemplo de tal tipo de violencia se encuentra en la República vecina: Venezuela. En dicho país, mediante la Ley sobre la Violencia Contra la Mujer y la Familia (Asamblea Nacional de Venezuela, 1998), se definen diversos tipos de violencia. Incluyendo en su texto normativo a la violencia psicológica, y como consecuencia e interpretación de la misma, se encuentra la violencia patrimonial, en la medida que considera que la privación de medios económicos contra la pareja.

Sin embargo, a pesar de que la ley se dirige a la "violencia contra la mujer" también se refiere a la familia. Por lo tanto, no se limita a una individualidad femenina, sino que incluye a cualquier sujeto del núcleo 
familiar independientemente del sexo de la persona, lo que, a todas luces, se ve plasmado en el documento legislativo. Ello se puede observar al examinar, con detenimiento, el texto. Dado que, en todo su desarrollo se menciona "u otro integrante de la familia" (Ley sobre la Violencia contra la Mujer y la Familia, 1998, pág. 2), dando lugar a que la violencia analizada, pueda ir encaminada también contra hombres.

En dicha norma, y tratándose de violencia psicológica, se observa como la pena impuesta por este tipo de violencia oscila entre los tres a los dieciocho meses, con una serie de agravantes. Entre los cuales resalta uno en particular de interpretación en el ordenamiento colombiano: "en perjuicio de personas discapacitadas, ancianos o menores de edad" (Asamblea Nacional de Venezuela, 1998, pág. 4).

\subsection{Panamá}

En su ordenamiento jurídico se adopta la Ley 82 de 2013 (Asamblea Nacional de Panamá, 2013). Encaminada a prevenir cualquier forma de violencia contra la mujer, establecer el feminicidio como delito y sancionar todo acto de violencia contra el género femenino.

De dicha ley se puede observar el concepto de violencia patrimonial diferenciado de la violencia psicológica. Se define así:

Acción u omisión, en el contexto de las relaciones desiguales de poder entre hombres y mujeres, que repercuta en el uso, goce, administración, disponibilidad o accesibilidad de una mujer a los bienes materiales, causándole daños, pérdidas, transformación, sustracción, destrucción, retención o destrucción de objetos, instrumentos de trabajo, documentos personales, bienes, derechos u otros recursos económicos, así como la limitación injustificada al acceso y manejo de bienes o recursos económicos comunes (Ley 82 de 2013, pág. 8)
Lo cual hace referencia a los elementos psicológicos que se mencionaron en apartado inicial, a la vez que incluye los elementos sociales desprendidos de dicha clase de violencia. Como lo son los dirigidos a la obtención de oportunidades laborales. Adicionalmente, la Asamblea Nacional de Panamá, en el artículo 13 de la citada ley, establece el derecho de las mujeres a la vida digna y libre de todo tipo de violencia, incluida la patrimonial o económica, adicionando el carácter de acceso y protección igual a los medios.

Sin embargo, resulta conveniente hacer hincapié en los artículos 200 y 214-A del Código Penal panameño ${ }^{36}$ (Asamblea Nacional de Panamá, 2015), en la medida hacen referencia a delitos con contenido de violencia patrimonial. El artículo 200 menciona a los actos de hostigamiento con contenido patrimonial, cuya pena será de cinco a ocho años de tratamiento terapéutico multidisciplinario en centro de salud. Mientras que el 214-A tipifica el delito de violencia económica o patrimonial contra la mujer, de forma independiente, bajo tres modalidades de ejecución: i) que afecte la libre disposición de su patrimonio ii) la suscripción de documentos y; iii) la destrucción u ocultación de los mismos.

En dicho ordenamiento jurídico, la pena se agrava cuando existe una relación marital, de concubinato o cualquier otro vínculo afectivo que reconozca alguna especie de institución familiar, ubicando la situación en el marco de la violencia intrafamiliar.

\subsection{España}

Al igual que en muchos de los ordenamientos jurídicos y bajo las tendencias sociales actuales, la legislación española, particularmente en Baleares, condenan situaciones atinentes solo a la violencia contra la mujer. Sin embargo, se pretenderá abstraer lo necesario para que la violencia

36. Modificado por el artículo 46 de la ley 82 (Asamblea Nacional de Panamá, 2013). 
patrimonial de género sea comprendida en la totalidad de los conceptos existentes ${ }^{37}$.

En España, la región de Baleares tiene su legislación en materia de protección de derechos e igualdad, más aún, tratándose de violencia patrimonial o económica. Así, la ley 11 (Parlamento de las Illes Balears, 2016) define la violencia económica como la privación, de manera intencional y que no tenga ningún justificante, de los recursos que permitan un adecuado desarrollo físico y, como lo resalta la ley, psicológico de las mujeres con respecto a la disposición de recursos de la convivencia o pareja.

Se observa pues, la conexión entre la violencia patrimonial, como consecuencia de la violencia intrafamiliar, con la inasistencia de recursos para la subsistencia. La ley también contiene disposiciones respecto de las prestaciones económicas, la vivienda y la inserción laboral, lo que a todas luces representa, y materializa, uno a uno, los elementos psicológicos, sociales, familiares de la violencia patrimonial sancionable. Tal como fue observado en apartados precedentes.

La norma pretende blindar la igualdad de hombres y mujeres en el hogar y en la administración de los recursos, con lo cual se establece un equilibrio en la representación de gastos y las finanzas del hogar de entre el cuarenta al sesenta por ciento por parte de cada uno de los cónyuges. Ello, claro está, considerando las circunstancias económicas de cada uno, independientemente del género de los esponsales o cohabitantes (2016).

\section{CONCLUSIONES}

A lo largo del presente estudio se presentaron diversos elementos para su correspondiente análisis, razón por la cual, se deprecan subtemas que fueron tratados en cada una de sus etapas.

Se debe desdibujar del imaginario general de la sociedad en el cual que las situaciones de género van encaminadas

37. Hombre, mujer, homosexual, lesbiana, transgénero, travesti, inter - género, etc. única y exclusivamente a violaciones a derechos, libertades, garantías y condiciones atribuibles al género femenino. Como se demostró, existen diversas concepciones del elemento género, sobre los cuales podemos ubicar a mujeres, infantes, hombres y toda clase de comunidades queer. Lo anterior se ve férreamente aclarado desde los conceptos de Naciones Unidas y grupos de lucha contra violaciones a los derechos de la mujer.

Ahora bien, tratándose de temas de violencia - e incluyendo género todas las categorías sexuales -, es conveniente mencionar las clasificaciones y tipos, los cuales, se mencionaron de manera clara $\mathrm{y}$ sus definiciones permitieron dar un sustento mayor al bagaje conceptual latente en la historia humana actual. Es decir, hablando de violencia física, se concluyó como puede ser infligida o ejercida por cualquier persona, independientemente de su género, en contra de su pareja, en donde su forma de identificación no constituye un determinante para la configuración de tal tipo de violencia. Por tanto, la violencia física, entendida como ese menoscabo corpóreo en contra de otra persona, por medio de diferentes mecanismos, puede, y es, ejercida independientemente del sexo o genitalidad de las personas que son parte o no de un núcleo familiar.

En cuanto a la violencia psicológica, cuya explicación nos lleva a resumirla como coacción y amenaza con el fin de minimizar al otro, se suma al argumento precitado. Teniendo en cuenta como puede ser ejercida entre cónyuges o compañeros/ as permanentes sin importar el sexo de los mismos o de la manera de conformación de la unión.

Por otra parte, se mencionó un tipo de violencia que sustenta los argumentos anteriores, teniendo en cuenta que se ha empezado a reconocer en el orden social del mundo que existe violencia doméstica contra el hombre. Sin embargo, en el caso de esa categoría, las denuncias se reducen significativamente bajo el entendido de la presión social, es decir, no existe una conciencia generalizada de no ridiculizar al 
hombre víctima. No obstante, se materializa como una especie de sub-eje transversal a las diferentes categorías de violencia. Allí se hace necesario aclarar que, en la violencia doméstica contra el hombre, existen sectores, principalmente ciertos activismos, que se resisten a reconocerla. Impidiendo su consideración dentro del esquema, con lo cual recalca la necesidad, al traer sobre la mesa la igualdad, de equiparar todo tipo de violencia dirigida contra cualquier miembro de la humanidad y no realizar distinciones que en sí mismas causan una discriminación flagrante.

Así mismo, la violencia sexual puede ser infligida por parte y en contra de cualquier miembro de un grupo familiar, hombre o mujer. No obstante, al igual que en las circunstancias previas, se hace más notorio tratándose de la causada por un hombre contra una mujer. Sin embargo, como se ha hecho suficiente hincapié, puede ser causada, aunque sea ridiculizada, aquella ejercida en contra del género masculino, ya sea por parte de los mismos o su contrario binario.

Finalmente, en cuanto a categorías de violencia se trata, se analizó la violencia patrimonial, la cual, constituye una categoría independiente de violencia, aún más, cuando se ejerce en contra de miembros del núcleo familiar. Es decir, en contra de alguno de los cónyuges, independientemente del sexo de los esponsales, cuando dependen económicamente del otro o cuando, teniendo los medios de subsistencia y capacidades laborales, el otro abusa de una posición de dominio para retirar de su haber el dinero que consigue. Ya sea ello en contra de los hijos o hijas menores y dependientes, de los hijos a sus padres cuando se encuentran en alguna condición de debilidad o incapacidad, etc. A lo cual se suma el hecho cuando, una parte del vínculo - marital, conyugal, de padre o madre a hijos e hijas, de hijos a padres, etc. - tiene, por ejemplo, la obligación de dar alimentos, y por esa fuerza o tipo de violencia no aporta lo que le corresponde, causando en su contrario un menoscabo en sus derechos $\mathrm{y}$ por tanto su integridad emocional, social, psicológica, etc. Configurando con lo anterior, al interior de una relación, una nueva forma de interpretación de la violencia intrafamiliar.

Asimismo, se observa la obligación de dar alimentos como la facultad de un sujeto llamado alimentado, o acreedor alimentario, de exigir de otra persona denominada alimentante o deudor alimentario, emolumentos y elementos necesarios para subsistir. Ello considerando que, para su exigencia, exista una relación de parentesco y otras circunstancias mencionadas anteriormente. Por tanto, resulta imperioso llevar a cabo una protección del derecho que le atañe al alimentado, es decir, desde diferentes perspectivas: desde el plano local o nacional, al plano internacional. Y, como consecuencia de ello, establecer sanciones cuando el alimentante no cumple, cumple defectuosamente o cumple de manera tardía con tal deber que le asiste.

En concordancia con lo anterior, se observa que a nivel internacional y/o supranacional, existen mecanismos de protección de ese derecho del alimentado y la obligación del alimentante. Declaraciones, convenios, acuerdos y tratados de los que Colombia es parte, que ha ratificado $y$ vinculado al ordenamiento jurídico y que, tratándose de versar en derechos humanos, hacen parte del bloque de constitucionalidad establecido en el artículo 93 de la Constitución Política de Colombia (1991). Entre ellos se encuentran: La Declaración Universal de Derechos Humanos, la Convención sobre la Obtención de Alimentos en el Extranjero, el Pacto Internacional de Derechos Económicos, Sociales y Culturales, la Convención Americana Sobre Derechos Humanos y la Convención Interamericana Sobre Obligaciones Alimentarias. Las cuales resaltan clara y taxativamente el derecho que asiste a quienes ostenten, o demuestren, ser acreedores de alimentos, la obligación del alimentante, pero, sin lugar a dudas, la obligación del Estado por velar y proteger dicho derecho y que se materialice su cumplimiento.

Como consecuencia, en el orden interno colombiano, desde diversos procedimientos y áreas de regulación, existen mecanismos 
para el reconocimiento, protección y garantía del derecho de alimentos y las correspondientes sanciones en caso de los incumplimientos mencionados ut supra.

Por tanto, se estableció que la obligación de alimentos, derivada del precepto legal del Código Civil, se refuerza mediante las leyes que han ratificado los pactos y convenciones internacionales en la materia. Seguido por el esclarecimiento de las sanciones que existen por el incumplimiento de la obligación. Así, se produjo del presente estudio, una línea concatenada de pasos para entender las sanciones por incumplimiento al pago de alimentos por parte del alimentante.

a) El proceso "administrativo", mediante el cual por un trámite conciliatorio se pueden fijar los alimentos y cuyo incumplimiento deviene en el proceso judicial por vía civil ante un juzgado de familia.

b) El proceso civil ante la jurisdicción de familia, mediante el cual se pueden fijar los alimentos y a cuyo incumplimiento nace la posibilidad de sancionar mediante el proceso ejecutivo de alimentos, en el que el juez puede embargar los bienes y cuentas (el patrimonio) del alimentante deudor. c) El proceso penal por inasistencia alimentaria cuando las etapas previas se han agotado $y$ no se ha dado cumplimiento, de manera injustificada, por parte del alimentante.

Ahora bien, en el contexto colombiano hace falta interpretación y reconocimiento legal de la violencia patrimonial. Sobre todo, teniendo en cuenta que, como se observó en los casos de Venezuela, Panamá y España, es necesario determinarla para poder establecer sanciones más fuertes por vía administrativa, civil y penal en caso de incumplimiento de la obligación de alimentar. Ello considerando como, en el ordenamiento colombiano, solo por vía jurisdiccional constitucional se ha reconocido ese tipo de violencia en casos particulares, pero no con un efecto erga omnes que permita tener en la ley nacional mecanismos más sólidos y severos frente a quien no cumple la obligación objeto de estudio de manera injustificada.

En resumen, la violencia patrimonial por impago de prestaciones de alimentos constituye inasistencia alimentaria y violencia intrafamiliar, concepto que se debe adoptar en Colombia para establecer un marco de severidad a la parte alimentante incumplida injustificadamente.

\section{BIBLIOGRAFÍA}

» Alberdi, I., \& Matas, N. (2002). La violencia doméstica Informe sobre los malos tratos a mujeres en España. Fundación Caixa. Barcelona: Fundación Caixa. Recuperado de http://pmayobre.webs.uvigo.es/pdf/la_violencia_domestica_informe_malos_tratos_a_mujeres_en_espana.pdf

»Alineados. (15 de febrero de 2018). Alineados servicios integrales y jurídicos. Recuperado de La obligación de alimentos en la legislación colombiana: http:// www.alineados.com.co/portal/?p=103

» Asamblea General de las Naciones Unidas. (10 de diciembre de 1948). Declaración Universal de Derechos Humanos. Resolución 217 A (III). París, Francia. Recuperado de https://www.un.org/es/universal-declaration-human-rights/

» Asamblea Nacional Constituyente de Colombia. (04 de julio de 1991). Constitución Política de Colombia. Bogotá D.C., República de Colombia: Gaceta Oficial.

» Asamblea Nacional de Panamá. (24 de octubre de 2013). Ley 82 de 2013. Que adopta medidas de prevención contra la violencia en las mujeres y reforma el Código Penal para tipificar el femicidio y sancionar los hechos de violencia contra la mujer. Ciudad de Panamá, Panamá: Gaceta de la república. Recuperado de https://oig. 
cepal.org/sites/default/files/2013_pan_ley82.pdf

» Asamblea Nacional de Panamá. (7 de octubre de 2015). CÓDIGO PENAL DE LA REPÚBliCA DE PANAMÁ. Se adopta el Código Penal de la República de Panamá. Ciudad de Panamá, República de Panamá. Recuperado de http://www.oas.org/juridico/pdfs/mesicic5_pan_res_ane_act_corr_2.pdf

» Asamblea Nacional de Venezuela. (3 de septiembre de 1998). Ley sobre la Violencia contra la Mujer y la Familia. Gaceta Oficial $N^{\circ}$ 36.531. Caracas, Venezuela: Gaceta Oficial $N^{\circ}$ 36.531. Recuperado de https://www.oas.org/dil/esp/Ley_sobre_violencia_contra_mujer_familia_Venezuela.pdf

» Castillero, 0. (11 de febrero de 2017). Psicología y Mente. Recuperado de Tipos de violencia de género: https://psicologiaymente.com/forense/tipos-violenciade-genero

» Comisión Interamericana de Derechos Humanos. (2015). Violencia contra Personas Lesbianas, Gay, Bisexuales, Trans e Intersex en América. Washington, Estados Unidos: CIDH. Recuperado de http://www.oas.org/es/cidh/informes/pdfs/ViolenciaPersonasLGBTI.pdf

» Congreso de la República de Colombia. (15 de abril de 1887). Código Civil. Ley 57 de 1887. Bogotá, Colombia: Gaceta Oficial. Recuperado de https://www.alcaldiabogota.gov.co/sisjurMantenimiento/normas/Norma1.jsp?i=39535

» Congreso de la República de Colombia. (4 de agosto de 1998). Ley 449 de 1998. Por medio de la cual se aprueba la "Convención Interamericana sobre Obligaciones Alimentarias", hecha en Montevideo, el quince (15) de julio de mil novecientos ochenta y nueve (1989). Bogotá, Colombia: Diario Oficial No. 43.360, de 11 de agosto de 1998. Recuperado de https://www.oas.org/dil/esp/Convencion_Interamericana_sobre_Obligaciones_Alimentarias_Colombia.pdf

» Congreso de la República de Colombia. (24 de julio de 2000). Ley 599 de 2000. Por medio de la cual se expide el Código Penal. Bogotá, Colombia: Gaceta oficial/Diario oficial. Recuperado de http://www.secretariasenado.gov.co/senado/basedoc/ ley_0599_2000.html

» Congreso de la República de Colombia. (5 de enero de 2001). Ley 640 de 2001. Por medio de la cual se modifican normas relativas a la conciliación y se dictan otras disposiciones. Bogotá, Colombia: Gaceta oficial, diario oficial. Recuperado de https://www.alcaldiabogota.gov.co/sisjur/normas/Norma1.jsp?i=6059

» Congreso de la República de Colombia. (8 de noviembre de 2006). Ley 1098 de 2006. Gaceta oficial. Bogotá, Colombia. Recuperado de https://www.oas.org/dil/ esp/Codigo_de_la_Infancia_y_la_Adolescencia_Colombia.pdf

» Congreso de la República de Colombia. (12 de julio de 2012). Ley 1564 de 2012. Código General del Proceso. Bogotá, Colombia: Diario oficial/Gaceta oficial. Recuperado de https://www.alcaldiabogota.gov.co/sisjur/normas/Norma1.jsp?i=48425

» Congreso de la República de Colombia. (20 de junio de 2019). Ley 1959 de 2019. POR MEDIO DE LA CUAL SE MODIFICAN Y ADICIONAN ARTÍCULOS DE LA LEY 599 DE 2000 Y LA LEY 906 DE 2004 EN RELACIÓN CON EL DELITO DE VIOLENCIA INTRAFAMILIAR. Bogotá, Colombia: Diario oficial/Gaceta oficial. Recuperado de https://www.lavozdelderecho.com/files/LEY_1959_DEL_20_DE_JUNIO_DE_2019_ violencia_intrafamiliar.pdf

» Congreso de la República del Perú. (23 de noviembre de 2015). LEY PARA PREVENIR, SANCIONAR Y ERRADICAR LA VIOLENCIA CONTRA LAS MUJERES Y LOS 
INTEGRANTES DEL GRUPO FAMILIAR. LEY N. a 30364. Lima, República del Perú.

» Das Dasgupta, S. (1 de noviembre de 2002). A Framework for Understanding Women's Use of Nonlethal Violence in Intimate Heterosexual Relationships. (S. Journals, Ed.) Violence Against Women, 8(11), 1364-1389. Recuperado de:https:// doi.org/10.1177/107780102237408

» Felson, R. (2002). Violence \& Gender Reexamined (Law and Public Policy: Psychology and the Social Sciences). (A. P. Association, Ed.) Washington D.C., Estados Unidos: American Psychological Association.

» Felson, R. (2002). Violence and gender reexamined. Washington, Estados Unidos: American Phycological Association.

» García, C. (julio de 2005). Psicoterapeutas.com. Recuperado de Violencia de Género: http://www.psicoterapeutas.com/violencia_de_genero.html

» Grupo de Investigación de la Violencia Doméstica. (2013). Proyecto sobre el estado del conocimiento del abuso por la pareja (PASK-Parthner Abuse State of Knowledge Project). Chicago: Board of the Peer-Reviewed Journal. Recuperado de https://domesticviolenceresearch.org/

» High Commissioner for Refugees of the United Nations. (2003). Sexual and Gender-Based Violence against Refugees, Returnees and Internally Displaced Persons: Guidelines for Prevention and Response. Ginebra: UN. Recuperado de https://www. unhcr.org/3f696bcc4.pdf

» House of Commons Home Affairs Office. (2008). Domestic Violence, Forced Marriage and 'honour'-Based Violence: Sixth Report of Session 2007-08 (Vol. 1). Londres, Inglaterra: London: The Stationery Office.

» Human Rights Watch. (2008). These Everyday Humiliations: Violence Against Lesbians, Bisexual Women, and Transgender Men in Kyrgyzstan. (H. R. (HRW), Ed.) Nueva York, Estados Unidos: Human Rights Watch (HRW). Recuperado de https:// www.hrw.org/report/2008/10/06/these-everyday-humiliations/violence-against-lesbians-bisexual-women-and

» Instituto Colombiano de Bienestar Familiar. (21 de enero de 2019). Instituto Colombiano de Bienestar Familiar "Cecilia De la Fuente de Lleras". Recuperado de ¿Cuál es la diferencia entre el proceso ejecutivo de alimentos y el de inasistencia alimentaria?: https://www.icbf.gov.co/cual-es-la-diferencia-entre-el-proceso-ejecutivo-de-alimentos-y-el-de-inasistencia-alimentaria

» Kilmartin, C., \& Allison, J. (2007). Men's Violence Against Women: Theory, Research, and Activism. Abingdon: Routledge.

» Ministerio de Justicia y Derechos Humanos de la Nación. (18 de marzo de 2016). Ministerio de Justicia y Derechos Humanos de la Nación. Recuperado de Violencia de género: tipo y modalidades de violencia: http://www.jus.gob.ar/areas-tematicas/ violencia-de-genero/tipos-y-modalidades-de-violencia.aspx

» Mujeres en Galicia. (2007). ¿Qué es la violencia de género? Informe sobre las mujeres en Galicia y violencia de género, Xunta de Galicia. Recuperado de http:// igualdade.xunta.gal/es/content/que-es-la-violencia-de-genero

» Nowinski, S., \& Bowen, E. (2012). Partner violence against heterosexual and gay men: Prevalence and correlates. Aggression and Violent Behavior, 17(1), 3652. Recuperado de: https://doi.org/10.1016/j.avb.2011.09.005

ONU mujeres. (31 de 0ctubre de 2010). Centro Virtual de Conocimiento para Po- 
ner Fin a la Violencia contra las Mujeres y Niñas. Recuperado de Definición de la violencia contra las mujeres y niñas: http://www.endvawnow.org/es/articles/295defining-violence-against-women-and-girls.html

» Organización de Estados Americanos. (22 de noviembre de 1969). Convención Americana Sobre Derechos Humanos. CONFERENCIA ESPECIALIZADA INTERAMERICANA SOBRE DERECHOS HUMANOS (B-32). San José, República de Costa Rica. Recuperado de https://www.oas.org/dil/esp/tratados_B-32_Convencion_Americana_sobre_Derechos_Humanos.htm

» Organización de Estados Americanos. (15 de julio de 1989). Convención Interamericana Sobre Obligaciones Alimentarias. CUARTA CONFERENCIA ESPECIALIZADA INTERAMERICANA SOBRE DERECHO INTERNACIONAL PRIVADO (B-54). Montevideo, Uruguay. Recuperado de http://www.oas.org/juridico/spanish/ tratados/b-54.html

» Organización de las Naciones Unidas. (20 de junio de 1956). Treaty series 3850. Convención sobre la Obtención de Alimentos en el Extranjero. Nueva York, Estados Unidos. Recuperado de https://assets.hcch.net/docs/d759a41f-548d-447c-9d9a2ca91093f60a.pdf

» Organización de las Naciones Unidas. (16 de diciembre de 1966). Pacto Internacional de Derechos Económicos Sociales y Culturales. Resolución 2200 A (XXI) de la Asamblea General de las Naciones Unidas. Nueva York, Estados Unidos. Recuperado de: https://www.ohchr.org/SP/ProfessionalInterest/Pages/CESCR.aspx

» Parlamento de las Illes Balears. (28 de julio de 2016). Ley 11/2016. igualdad de mujeres y hombres. Palma de Mallorca, Islas Baleares, Reino de España: Boletín oficial de España BOE. Recuperado de: https://www.boe.es/buscar/pdf/2016/ BOE-A-2016-7994-consolidado.pdf

» Pérez, J., \& Escobar, A. (2011). Prevención de la violencia de género. Madrid: Grupo 5 Editorial.

» Rojina, R. (2006). Derecho Civil mexicano (Vol. II). Ciudad de México, Estados Unidos Mexicanos: Porrua.

» Salem, D. (21 de mayo de 2013). Cision PRWeb. Recuperado de Estudio sin precedentes sobre violencia doméstica afirma la necesidad de reconocer a las víctimas masculinas: http://www.prweb.com/printer/10741752.htm

» Sentencia C - 184 de 1999, Expediente LAT-119 (Corte Constitucional de Colombia 24 de marzo de 1999). Recuperado de: http://www.corteconstitucional. gov.co/relatoria/1999/C-184-99.htm

» Sentencia C - 305 de 1999, Expediente LAT-140 (Corte Constitucional de Colombia 5 de mayo de 1999). Recuperado de: http://www.corteconstitucional.gov. co/relatoria/1999/C-305-99.htm

» Sentencia C-156 de 2003, expediente D-4198 (Corte Constitucional 25 de febrero de 2003). Recuperado de: http://www.corteconstitucional.gov.co/ relatoria/2003/C-156-03.htm

»Sentencia T - 012 de 2016, expediente T- 4.970.917 (Corte Constitucional de Colombia 22 de enero de 2016). Recuperado de: http://www.corteconstitucional. gov.co/relatoria/2016/t-012-16.htm

» Sentencia T-506 de 2011, expediente T-2.936.513 (Corte Constitucional de Colombia 30 de junio de 2011). Recuperado de: http://www.corteconstitucional.gov. 
co/relatoria/2011/T-506-11.htm

» SISMA Mujer. (22 de enero de 2016). concepto para sentencia T012 de 2016. Sentencia T-012 de 2016 Corte Constitucional de Colombia. Bogotá, Colombia: Gaceta Oficial. Recuperado de: http://www.corteconstitucional.gov.co/ relatoria/2016/t-012-16.htm

»Woods, M. (2 de marzo de 2015). Web citation. Recuperado de: The Rhetoric and Reality of Men and Violence: http://static1.1.sqspcdn.com/static /f/929640/14202976/1316317511587/woods_nmhc_07.pdf?token=Gg4mgL\% 2Bd\%2FLYeeaPQqGg9vUW1Fo4\%3D 